\title{
A ARTE MÓRBIDA: PROCEDIMENTOS NARRATIVOS, HORROR CÓSMICO E DESESTABILIZAÇÃO DO HISTÓRICO EM “O MODELO DE PICKMAN" DE H. P. LOVECRAFT
}

Ana Claudia Aymoré Martins (UFAL)

Pedro Fortunato de Oliveira Neto (UFAL)

Recebido em 05 mar 2017. Ana Claudia Aymoré Martins possui graduação em Aprovado em 30 mar 2017. História pela Pontifícia Universidade Católica do Rio de Janeiro (1993), mestrado em História Social da Cultura pela Pontifícia Universidade Católica do Rio de Janeiro (1995) e doutorado em Letras (Ciência da Literatura) pela Universidade Federal do Rio de Janeiro (2003). Atualmente é professora associada da Universidade Federal de Alagoas. Tem experiência na área de Letras, com ênfase em Teoria Literária, e na área de História, com ênfase em História Social da Cultura, atuando principalmente nos seguintes temas: literatura brasileira, literatura contemporânea, teoria literária, nação e literatura e história.

Pedro Fortunato de Oliveira Neto é mestrando em estudos literários pela Universidade Federal de Alagoas. Tem experiência na área de Letras, com ênfase em Literaturas Estrangeiras Modernas, atuando principalmente nos seguintes temas: distopia, pósapocalipse, utopia e estudos culturais.

Resumo: O artigo trata de analisar o conto "O modelo de Pickman" (1926), de H. P. Lovecraft, tomando 
como ponto de partida seus principais procedimentos narrativos, de modo a observar como esses elementos se relacionam, em primeiro lugar, com a teoria lovecraftiana do horror cósmico, e, em segundo lugar, com quadros históricos de referência, mediados principalmente pelos campos da história da arte e da história cultural.

Palavras-chave: H. P. Lovecraft; Modelo de Pickman; Literatura fantástica; Procedimentos narrativos; Horror cósmico; História.

Abstract: The paper examines HP Lovecraft's short story "Pickman's Model" (1926), taking as its starting point its main narrative procedures, in order to observe how these elements relate first to the Lovecraftian theory of Cosmic horror, and, secondly, with historical frames of reference, mainly mediated by the fields of art history and cultural history.

Keywords: H. P. Lovecraft; Pickman's Model; Fantastic Literature; Narrative procedures; Cosmic horror; History.

Howard Philips Lovecraft (1890-1937), um dos maiores e mais conhecidos escritores de horror em língua inglesa, e reconhecido como o pai da weird fiction, escreveu dezenas de contos, algumas novelas e também poesia. Em suas narrativas, Lovecraft criou todo um universo fictício atormentado por monstros que acabaram se tornando famosos na cultura pop, como a impronunciável entidade cósmica do icônico conto "O Chamado de Cthulhu", que aparece em games, músicas de heavy metal, histórias em quadrinhos, filmes e várias outras expressões de cultura de massa.

Outro de seus contos que também tem influenciado a produção cultural além da literatura é "O modelo de Pickman", tendo sido adaptado para a televisão, pela série Night Gallery, em 1 de 
dezembro de 1971, e que segue inspirando produções audiovisuais ${ }^{1}$ diversas. Embora menos conhecido do grande público que "O Chamado de Cthulhu", "O Modelo de Pickman", é, no entanto, uma referência fundamental para os estudiosos da obra lovecraftiana, pois é nele que, segundo Carl Sederholm (2006), "Lovecraft explora seu narrador para modelar a experiência do terror cósmico e seus efeitos" (p.348, tradução nossa); ou seja, Lovecraft teria usado, nesse conto, o próprio narrador-personagem para demonstrar exatamente os efeitos que a sua teoria de um terror cósmico poderia ter em seu possível público leitor. Mas seria possível desvincular totalmente o horror cósmico lovecraftiano de suas possíveis relações com o horizonte histórico-cultural a que pertence, mesmo que seja para desestabilizar ou transgredir noções positivistas e banalizadas de realidade? Pois, como nos mostra David Roas num de seus mais influentes artigos sobre o gênero fantástico,

O fantástico [...] está inscrito permanentemente na realidade, a um só tempo apresentando-se como um atentado contra essa mesma realidade que o circunscreve. [...] E a literatura fantástica nos obriga, mais do que nenhuma outra, a ler os textos referencialmente [...]: sabemos que um texto é fantástico por sua relação (conflituosa) com a realidade empírica. (2014, p.52-53)

Assim, a presente análise de "O Modelo de Pickman" pretende não apenas demonstrar o que é a teoria do terror cósmico na obra de Lovecraft, mas que procedimentos narrativos foram adotados para criar seus efeitos sob a personagem narradora do conto, e como esses procedimentos se relacionam: a) com sua teoria geral

1 Sendo as mais famosas Chilean Gothic (2008), dirigida por Ricardo Harrington, e o curta Pickman's Model (2012), dirigido por Mark Philip Lichtenstein. 
de um horror cósmico que, para Lovecraft, definiria o verdadeiro conto de horror; e b) com a construção de uma narrativa que interrelaciona o insólito ficcional a quadros sócio-históricos de referência, simultaneamente criando e subvertendo as pontes entre real e imaginário.

\section{UM HOMEM DE SORTE POR NÃO TER ENLOUQUECIDO}

Provavelmente escrito em setembro de 1926 e publicado pela primeira vez na revista Weird Tales de outubro de 1927 (JOSHI e SCHULTZ, 2001, p.204), "O Modelo de Pickman" é uma narrativa curta em que o narrador autodiegético, Thurber, conta ao seu amigo Eliot por que deixou de se associar ao pintor Richard Upton Pickman de Boston, que havia desaparecido recentemente. No conto, encontramos um Thurber mentalmente perturbado a contar sua relação com Pickman, como manteve sua amizade mesmo depois que todos o abandonaram por causa do grotesco de suas pinturas, e como foi levado para seu estúdio secreto para ver suas principais obras. No estúdio, Thurber se depara com algumas das pinturas mais grotescas e demoníacas de Pickman, aterrorizandose ao ponto de não conseguir conter as expressões de um intenso pavor. Então, depois de sair do estúdio, o narrador descobre que tinha inadvertidamente tomado uma fotografia afixada a uma das telas, pensando que seria uma mera foto de fundo cênico, e fica horrorizado ao descobrir que era uma imagem do próprio monstro - "Mas por Deus, Eliot, era uma fotografia!" (LOVECRAFT, 2015, p.106) -, revelando, assim, no encerramento da narrativa, o motivo de seu desequilíbrio mental ${ }^{2}$.

2 Uma das primeiras coisas que é digna de nota quando se lê o conto é que não apenas Lovecraft utilizou do narrador-personagem, como colocou algumas indicações de que 
Considerando-se que a loucura não é algo desejável em uma sociedade com padrões humanistas pautados na razão, o estado mental do narrador de "O Modelo de Pickman" já funciona como o primeiro procedimento utilizado para introduzir o clima de terror que Lovecraft irá desenvolver no decorrer do conto. O tema da perda de sanidade psíquica do narrador é, de fato, bastante recorrente em Lovecraft (como, em linhas gerais, constitui-se como um leitmotiv da literatura fantástica desde textos fundadores como o célebre "O homem da areia" de E. T. A. Hoffman ou muitos dos contos de Poe), aparecendo também em outras de suas obras, como "O Chamado de Cthulhu" e Nas montanhas da loucura. Aqui, destacamos o início de "O Chamado de Cthulhu":

A coisa mais misericordiosa do mundo é, segundo penso, a incapacidade da mente humana em correlacionar tudo o que sabe. Vivemos em uma plácida ilha de ignorância em meio a mares negros de infinitude, e não fomos feitos para ir longe. As ciências, cada uma emprenhando-se em seus próprios desígnios, até agora nos prejudicaram pouco; mas um dia a compreensão ampla de todo esse conhecimento dissociado revelará terríveis panoramas da realidade e do pavoroso lugar que nela ocupamos, de modo que ou enlouqueceremos com a revelação ou então fugiremos dessa luz fatal em direção à paz e ao sossego de uma nova idade das trevas. (LOVECRAFT, 2015, p.64 - grifo nosso).

esse narrador estaria passando por uma perturbação psíquica que beira a loucura. Os três primeiros parágrafos já contêm essas marcas textuais. No primeiro Thurber repreende seu amigo por zombar dele - "Você não precisa achar que sou louco, Eliot" (LOVECRAFT, 2015, p.94) -; no segundo ele afirma estar nervoso e ter a sorte de ainda possuir lucidez após a experiência traumática no ateliê de Pickman - "Eu sei que estou mais nervoso do que estava quando você me viu ano passado [...] Tenho bons motivos, só Deus sabe, e considero-me um homem de sorte por não ter enlouquecido" (LOVECRAFT, 2015, p.94) -; e no terceiro ele afirma que "os meus nervos já não são mais os mesmos" (LOVECRAFT, 2015, p.94). 
E o início de Nas montanhas da loucura:

Vejo-me obrigado a falar porque os homens de ciência recusaram-se a seguir os meus conselhos sem saber por quê. É muito a contragosto que revelo as razões que tenho para me opor à possível invasão da Antártida - acompanhada de uma ampla busca por fósseis e projetos para perfurar e derreter vários pontos da ancestral calota polar em grande escala - e reluto ainda mais porque $o$ meu alerta pode ser em vão. [...] No fim das contas, nada me resta senão confiar no juízo e no renome de uns poucos líderes científicos que gozam, por um lado, do pensamento independente necessário para analisar a execranda capacidade persuasiva dos meus dados à luz de certos ciclos míticos primordiais e deveras espantosos; e, pelo outro, de influência suficiente para impedir o mundo exploratório como um todo de levar a cabo qualquer plano brusco e demasiado ambicioso na região daquelas montanhas da loucura. (LOVECRAFT, 2015, p.546 - grifo nosso)

Os narradores dos três contos iniciam seus relatos em estado de certa perturbação mental, e, conforme os contos avançam, o público leitor entende que tal condição advém de uma experiência traumática que lhes trouxe a revelação de algo horrível: os quadros miméticos de Pickman, em "O Modelo de Pickman", os relatos sobre a criatura Cthulhu, em "O Chamado de Cthulhu", e o encontro de entidades monstruosas durante escavações nas montanhas na Antártida, em Nas montanhas da loucura.

O desequilíbrio psíquico dessas personagens narradoras é bastante significativo se considerarmos a própria teorização de Lovecraft sobre o que ele considerava ser o legítimo conto de horror. $\mathrm{O}$ autor afirma que 
[o] verdadeiro conto de horror tem algo mais que sacrifícios secretos, ossos ensanguentados ou formas amortalhadas fazendo tinir correntes em concordância com as regras [...] Há que estar presente uma certa atmosfera de terror sufocante e inexplicável ante forças externas ignotas [...] uma suspensão ou derrogação particular das imutáveis leis da Natureza, que são a nossa única defesa contra as agressões do caos e dos demônios do espaço insondado. (LOVECRAFT, 1987, p.4-5)

Para Lovecraft, portanto, o conto de horror deve lidar com a suspensão das leis da natureza, que deixe a humanidade em um estado de vulnerabilidade. Um narrador em seu perfeito estado mental não experimentaria tal concepção de horror de forma tão significativa, e por isso, embora Lovecraft tenha contos escritos com narração em terceira pessoa, suas obras mais aclamadas utilizam o recurso do narrador autodiegético ${ }^{3}$. No entanto, diferente de vozes narrativas de outros contos de horror, como o "Gato Preto", de Edgar Allan Poe, narrado por uma personagem que tem problemas com alcoolismo, ou "Ligeia", do mesmo autor, cujo narrador parece sofrer de alucinações após a morte da amada (portanto, o que a teoria literária chama habitualmente de narrador não-confiável), o narrador de "O Modelo de Pickman", demonstra ser um homem educado e esclarecido nas artes visuais, alguém cuja palavra poderia ser digna de confiança - mesmo ao confrontar-se com a experiência aterrorizante trazida por um

3 Todorov, em sua teorização bastante conhecida sobre a literatura fantástica, afirma que no discurso do fantástico "o narrador diz habitualmente 'eu'” (1992, p.90), justamente porque em sua teorização o que marca o fantástico é a hesitação, a dúvida que perpassa a narrativa para vir a se estabelecer no leitor através do pacto ficcional - tratam-se de acontecimentos reais ou resultantes de uma imaginação perturbada, possíveis de serem explicados pelas leis que regem o mundo visível ou sobrenaturais? -, em contraste com a certeza de desconexão do real que caracteriza o gênero maravilhoso. 
artista macabro. De fato, como nos aponta Remo Ceserani, o narrador-personagem do conto fantástico é

quase sempre pertencente, pela formação mental ou pela profissão, à cultura dominante; os protagonistas são muitas vezes médicos ou cientistas, dotados de uma dedicação oitocentista pela sua ciência e os seus paradigmas de juízo, os quais vêm postos em confronto com personagens de outra natureza, artistas, visionários, viajantes fantásticos, e são levados pelo contato e pela experiência perturbadora a redescobrir dentro de si, e através de eventos vividos ou narrados, formas de conhecimento ou sensações pertencentes a modelos culturais até então abandonados. (CESERANI, 2006, p.104)

Da mesma maneira, os narradores de "O Chamado de Cthulhu", um antropólogo, e Nas Montanhas da Loucura, um geólogo, não parecem ser personagens que ficariam loucos por qualquer motivo ou que sairiam a inventar histórias de terror a partir de algum acontecimento banal. A impressão que esses personagens passam é de pessoas insuspeitas que passaram por experiências extraordinárias, razão pela qual sua própria sanidade Ihes foi desafiada, e, ao que parece, Lovecraft os coloca como perturbados não para descreditar seus relatos, mas de modo a preparar o público leitor para uma experiência narrativa terrificante, algo digno de desvelar a fragilidade humana diante da monstruosidade existente no universo. Simultaneamente, o declínio da razão em Lovecraft como traço fundamental do terror cósmico (e que se expressa frequentemente em seus contos e novelas através desse narrador mentalmente perturbado) entrelaça-se substancialmente com uma perspectiva histórica. Produzindo a parte mais significativa 
de sua obra ficcional entre as décadas de 1920 e 1930 - marcadas pela falência brutal das expectativas iluministas de progresso, racionalidade e conforto material da civilização ocidental, num cenário de amplificação e barbárie progressiva das guerras, crise do capitalismo e ascensão de ideologias reacionárias e totalitárias - Lovecraft frequentemente assinala, através desse procedimento de composição, o dispositivo crítico das ideologias da modernidade burguesa, de seu caráter relativo, instável, excludente e arbitrário.

O segundo procedimento para a criação do clima favorável à revelação final do horror cósmico está na excêntrica caracterização da personagem antagonista Richard Upton Pickman. O pintor de Boston, como citado acima, funciona como um tipo de mediador entre o narrador-personagem ( $\mathrm{e}$, nesse caso, também o público leitor) e a experiência com o macabro ${ }^{4}$. Pickman é primeiramente descrito como alguém de quem o protagonista quer distância no presente, para, logo em seguida, ser dito também que ele está desaparecido, sendo procurado pela polícia, e que os outros apreciadores de arte o teriam abandonado por não suportar sua maneira macabra e a morbidez de sua arte: "Reid [...] disse que Pickman deveria ser anormal ou excêntrico ao extremo. Imagino que você tenha dito a Reid [...] que os nervos ou a imaginação dele ficavam muito abalados com as pinturas de Pickman" (LOVECRAFT, 2015, p.96). Um pouco adiante, Thurber traz uma informação hereditária sobre Pickman que o liga ainda mais ao macabro, ao monstruoso e ao sobrenatural, mas dessa vez como 
uma relação projetada no tempo, vinculada ao passado: afirma que Pickman seria descendente de uma das bruxas de Salem, "e que algum antepassado dele foi enforcado por bruxaria em 1692" (LOVECRAFT, 2015, p.96).

Todos esses detalhes podem fazer com que o/a leitor/a comece a perceber desde as primeiras páginas do conto que Pickman será o mediador entre Thurber e a experiência do horror cósmico. No entanto, ele é também o mediador entre o que está sendo narrado (aquilo que é, portanto, efetivamente apresentado ao leitor na forma textual) e o que é visto pelo narrador, na medida em que se aproxima de personagens históricas das artes visuais que são famosas por sua arte mórbida. Ao longo do relato, o narrador as compara com Pickman, destacando, porém, que esse último teria uma técnica que produziria um horror ainda maior do que a desses artistas:

Não preciso dizer a você por que um Fuseli faz nossos ossos literalmente se enregelarem, enquanto um frontispício de história de terror só nos faz rir. Existe alguma coisa que esses sujeitos captam - algo além da vida - que eles conseguem nos fazer captar por um breve instante. Com Doré era assim, com Sime é assim. Com Angarola, de Chicago, é assim. E quanto a Pickman - nenhum homem jamais foi como ele e, por Deus, espero que jamais seja outra vez. (LOVECRAFT, 2015, p.95)

E, também, associa esse caráter inquietante à representação dos rostos, o elemento fundamental da arte do retrato, tão cara à modernidade ocidental desde o Renascimento:

Você lembra que o forte de Pickman era os rostos. Acho que ninguém, desde Goya, foi capaz de 
representar o inferno em estado bruto nos traços de um rosto ou em uma expressão contorcida. $\mathrm{E}$ antes de Goya você precisa voltar até os sujeitos medievais que fizeram os gárgulas e as quimeras em Notre-Dame e em Mont Saint-Michel. (LOVECRAFT, 2015, p.96)

É bastante significativo o fato de que Lovecraft utiliza essas personagens históricas para tentar demonstrar o tipo de arte de Pickman. É difícil expressar com palavras o caráter terrificante de uma arte que é visual, mas ao comparar a pintura de Pickman com exemplos artísticos do mundo extratextual, Lovecraft traz uma base iconográfica para que o público leitor possa ter como referência: basta olhar, por exemplo, para as diversas reproduções do quadro O Pesadelo (1781), do pintor suíço Fuseli (1741-1825), ou para as ilustrações infernais da Divina Comédia, feitas por Gustave Doré (1832-1883), ou, ainda, para as imagens da grotesca pintura de Saturno devorando um filho (1819-1823), de autoria do pintor espanhol Francisco de Goya (1746-1828), para se ter uma ideia do tipo de arte macabra que Pickman estaria pintando.

Segundo Thurber, o artista que produz essa arte insólita e aterradora seria o tradutor de um mundo suprassensível pelo qual transita - "Bem, devo dizer que um artista realmente excêntrico tem um tipo de visão que cria modelos, ou invoca alguma coisa equivalente a cenas reais do mundo espectral em que vive" (LOVECRAFT, 2015, p.95) - e que se associa indelevelmente a um passado sombrio. Thurber não pode senão concluir que ele não aguentaria sequer vislumbrar o que Pickman teria visto, e chega ao ponto mesmo de duvidar da humanidade do pintor: "Meu Deus, eu 
não estaria vivo hoje se tivesse visto o que aquele homem - se é que era um homem - via!" (LOVECRAFT, 2015, p.95 - grifo nosso).

Nesse momento, o conto de Lovecraft entrelaça dois dos motivos mais característicos da literatura fantástica: o tema do duplo e o caráter subjetivo/desafiador da imagem. Ceserani, ao analisar os procedimentos narrativos e temas principais em "O homem da areia", destaca que o conto de Hoffmann, ao colocar em destaque o uso de instrumentos óticos, superfícies espelhadas e representações imagéticas, "põe em cena os problemas da força alucinatória da imagem, da subjetividade da percepção, da divisão em duplos e assim por diante" (2006, p.26). De forma análoga, podemos considerar o fato de que grande parte do caráter extraordinário e terrível do modelo de Pickman consiste, em primeiro lugar, em sua carga imagética - a referência do quadro era uma fotografia, portanto algo que esteve lá ${ }^{5}$, a que o pintor teve acesso e registrou, em primeiro lugar, de forma objetiva ${ }^{6}$ durante seus trânsitos para além da banalidade cotidiana, e que o narrador porta como prova inequívoca de sua experiência extraordinária ${ }^{7}$ - mas também na ambiguidade que se instala em

5 O que Barthes, em A câmara clara (1984, p.115), denomina de referente fotográfico.

6 Considerando a particularidade do conto enquanto gênero literário, é bastante conhecida a imagem criada pelo escritor argentino Julio Cortázar que compara o romance a um filme e o conto a uma fotografia (1993, p.151). O que Cortázar quis dizer é que, diferente do romance, o conto é uma narrativa curta, portanto, condensada e de percepção quase sincrônica. Não pode perder tempo com trivialidades, todos os seus detalhes devem ser relevantes à trama. No caso do conto de Lovecraft aqui analisado, o fato da narrativa convergir para o vislumbre de uma fotografia também aponta para um procedimento metaficcional, que destaca os procedimentos narrativos na própria economia do texto - uma das características do modo fantástico de narração, segundo Ceserani (2006, p.68-69).

70 que nos leva, também, a um outro procedimento narrativo usual do fantástico, segundo Ceserani: o objeto mediador, "que, com sua concreta inserção no texto, se torna o testemunho inequívoco do fato de que o personagem-protagonista realizou uma viragem" (2006, p.74). 
relação ao artista, constituindo-se, num jogo especular entre o pintor e seu modelo, também, em última análise, seu duplo, na ruptura monstruosa do mito da individualidade burguesa autoafirmada que o insólito ficcional frequentemente personifica. A repulsa da sociedade letrada a Pickman é ressaltada diversas vezes ao longo da narrativa, de forma que o aproxima de outras personagens emblemáticas da representação do eu fragmentado na literatura fantástica da modernidade, como o célebre Dr. Jeckyll/Mr. Hyde da novela de Stevenson:

Ele disse que Pickman o repelia mais a cada dia, e que nos últimos tempos quase o assustava que os traços e a expressão do rosto dele aos poucos se desenvolviam de um modo que não o agradava; de um modo que não era humano (LOVECRAFT, 2015, p.96)

Em outra passagem do conto, durante a visita ao estúdio do artista, o narrador se depara com dois quadros opostos e complementares: o primeiro mostra uma criança, que teria sido raptada por criaturas malignas, sendo ensinada por monstros repulsivos a se alimentar de forma bestial; no segundo, em meio a uma família puritana numa cena doméstica, o rosto de um garoto assume os contornos degradados dos seres inumanos, enquanto reproduz, em forma de autorretrato (que é também um signo especular, reflexivo, característica do duplo literário), os traços de seu criador:

Todos os rostos [no quadro], com a exceção de um, tinham uma expressão nobre e reverente, mas aquele um refletia o escárnio das profundezas. Era o rosto de um garoto, sem dúvida tido por filho daquele pai tão devoto, mas que na verdade 
tinha parentesco com os seres impuros. Era a outra criança trocada - e, num espírito de suprema ironia, Pickman havia pintado o rosto do garoto com notável semelhança ao seu próprio. (LOVECRAFT, 2015, p.101 - grifos nossos)

Por fim, não podemos deixar de observar que, quando a narrativa se inicia, e a história da terrível experiência de Thurman no ateliê do artista começa a ser contada retrospectivamente a seu interlocutor, Pickman é um homem foragido. A elipse a respeito do suposto crime cometido pelo pintor o aproxima, de certo modo, do "tipo e do gênio do crime profundo" do famoso conto de Poe (1986, p.400), aquele que atravessa os vãos da modernidade, e cuja opaca presença é como o livro alemão que Er lässt sich nicht lesen.

\section{UMA ESTRANHA REGIÃO SOMBRIA}

A escolha do cenário para um conto de horror é algo extremamente significativo. Lugares mal-assombrados, cemitérios, velhos castelos - há toda uma gama de locais tradicionalmente associados com o terror na cultura popular. A ligação entre antiguidade e assombração é algo comum a histórias de terror, como o velho castelo mal-assombrado em 0 Castelo de Otranto, para Lovecraft "o fundador da história de horror literária como forma permanente" (1987, p.14). O tema de um lugar antigo assombrado por espíritos é, também, algo bastante comum na obra do autor nascido em Rhode Island. Em "O Chamado de Cthulhu", o monstro de nome impronunciável descansa em sua casa na antiga cidade submersa de R'lyeh, e na novela Nas montanhas da loucura, o horror se passa em uma pré-humana cidade subterrânea, encontrada por escavadores na Antártida. Em "O 
modelo de Pickman" a escolha do espaço marcado pela distância do passado histórico não está apenas presente como elemento da narrativa, mas também de forma metaficcional, sendo um tema efetivamente discutido pelas personagens do conto. Na primeira fala atribuída ao sinistro Pickman, "A Back Bay não é Boston - ainda não é nada, porque não teve tempo de guardar memórias e atrair espíritos locais" (LOVECRAFT, 2015, p.97). O pintor deseja, como lugar de constituição de sua arte, um lugar mais antigo, povoado por espectros e marcado por acontecimentos terríveis: "mas eu quero fantasmas humanos - fantasmas de seres inteligentes o bastante para terem visto o inferno e compreendido o que viram" (LOVECRAFT, 2015, p.97).

Pickman descreve com nostalgia o passado desacreditado no presente histórico do conto por causa da ignorância do século $X X^{8}$. Há aqui um conflito entre uma espécie de sabedoria sobre eventos sobrenaturais pertencentes ao passado - "Gerações e mais gerações viveram e sofreram e morreram por lá, e numa época em que as pessoas não tinham medo de viver e sofrer e morrer" (LOVECRAFT, 2015, p.97) - e uma espécie de ceticismo ignorante do presente cientificista do século $X X-$ "O único aspecto positivo do presente é que ele é estúpido demais para fazer perguntas detalhadas acerca do passado" (LOVECRAFT, 2015, p.98) -, mais um traço da crítica à razão iluminista de que falamos acima. Num estudo fundamental sobre as mentalidades coletivas no contexto da era moderna, o historiador francês Jean Delumeau afirma que "Outrora, o passado não estava realmente Thurber cita o autor de fantasia, horror e ficção científica Clark Ashton Smith, que apenas começou a escrever por volta de 1912 (JOSHI e SCHULTZ, 2001, p. 265). 
morto e podia irromper a qualquer momento, ameaçador, no interior do presente. Na mentalidade coletiva, muitas vezes a vida e a morte não apareciam separadas por um corte nítido" (2009, p.84). Frequentemente, no campo das mentalidades e da cultura popular, diz Delumeau, essa irrupção do passado sobre o presente se dá através da aparição dos mortos ou de monstruosidades ancestrais. No entanto, muitas vezes essa relação com um tempo pretérito oculto pela distância temporal ocorre num misto de assombro e fascínio, e, sobretudo quando se trata de um período envolto em concepções vulgarizantes e superficiais - como ocorre frequentemente com o medievo - o que contribui para a formação daquilo de Carlo Ginzburg (1991, p.119-130) denominou, em um dos seus artigos menos conhecidos, de estereótipo de conjunto: nesse caso, ver a Idade Média sob as lentes estereotipadas da "idade das trevas", um período marcado pelas superstições, pela magia e pelo poder das forças ocultas e sombrias.

Pickman olha para o passado histórico distante com nostalgia, por acreditar no contato com os horrores do sobrenatural a tal ponto que chega a julgar que até as construções modernas não suportariam os acontecimentos marcantes do passado: "Posso mostrar para você casas que estão de pé há mais de dois séculos e meio; casas que presenciaram coisas que fariam uma casa moderna desabar em ruínas" (LOVECRAFT, 2015, p.97). Esse conhecimento antigo, como a bruxaria de Salem negada pela sociedade materialista, seria justamente o horror cósmico que desestabiliza o humano perante o incontrolável sobrenatural. Para Lovecraft (1987, p.7), em sua teorização sobre a literatura de horror, "O terror cósmico aparece como ingrediente do mais remoto folclore de 
todos os povos, cristalizado nas mais arcaicas baladas, crônicas e textos sagrados", sendo que, na perspectiva da estudiosa Viktória Prohászková (2012), “A essência do medo cósmico reside em alguma intuição instintiva que pode revelar o que a sociedade materialista nega" (p.10, tradução nossa). Portanto, esse conhecimento antigo, registrado em representações culturais quase esquecidas, embora abafado pela modernidade, só poderia ser acessado em um lugar adequado, no caso um lugar antigo e assombrado pelo passado.

Por isso Pickman precisa levar Thurber para seu estúdio em North End. Apenas nesse lugar ideal é que se pode ter acesso ao espírito noturno de um horror antigo e pintar coisas ainda mais macabras do que aquelas que já haviam escandalizado todos os críticos de arte, à exceção de Thurber. Então, uma vez liberadas, essas forças ancestrais abrem caminho sobre o presente, invadindo a vida cotidiana - como é representado nos "estudos modernos" do pintor:

Nesse ponto Pickman já havia acendido uma lamparina no cômodo ao lado e [...] segurou a porta aberta para que eu passasse; perguntou se eu gostaria de ver seus "estudos modernos". Eu não tinha conseguido comunicar a ele as minhas impressões - o pavor e a repulsa me emudeciam - mas acho que ele entendeu o que se passava e considerou tudo aquilo um grande elogio. [...] não esqueça que eu mal havia recuperado o fôlego e me acostumado àquelas criaturas pavorosas que transformavam a Nova Inglaterra colonial em um anexo do inferno. Mas, bem, apesar de tudo isso o cômodo seguinte me fez soltar um grito, e precisei me agarrar ao vão da porta para não cair. O primeiro aposento mostrava grupos de ghouls e de bruxas à solta no mundo de nossos antepassados, mas esse 
outro trazia o horror para a nossa vida cotidiana! [...] Ele tinha um estudo chamado Acidente no metrô em que um bando de criaturas vis saía de alguma catacumba desconhecida por uma rachadura no piso da estação na Boston Street e atacava a multidão de pessoas que aguardava na plataforma [...]. Uma tela repugnante parecia mostrar uma parte de Beacon Hill tomada por exércitos dos monstros mefíticos enfiados em inúmeras tocas que conferiam ao chão o aspecto de um favo de mel. [...] uma outra composição me chocou mais do que todas as outras - uma cena no interior de uma arcada desconhecida, onde inúmeras criaturas amontoavam-se em torno de uma outra, que tinha nas mãos um famoso guia de Boston e estava sem dúvida lendo em voz alta. Todos apontavam para uma certa passagem, e cada um daqueles rostos parecia tão desfigurado pelas risadas epilépticas e reverberantes que eu quase pude ouvir os ecos demoníacos. (LOVECRAFT, 2015, p.101-102)

E provocando, no perturbado narrador, um medo que equivale antigos porões a modernas estações de metrô, borrando as distâncias entre passado e presente:

[...] acho que agora você deve entender por que não entro mais em metrôs nem em porões. Foi foi por causa de uma coisa que eu achei no bolso do meu casaco na manhã seguinte. [...] Sim, foi por causa daquele papel que eu me afastei de Pickman. (LOVECRAFT, 2015, p.106)

\section{UMA BLASFÊMIA COLOSSAL}

Em "O Modelo de Pickman", Lovecraft utiliza a arte como o meio através do qual a revelação monstruosa causadora do horror cósmico atua sobre o protagonista. No estúdio do pintor de Boston, 
Thurber, alguém que não se choca com a estética macabra e estava mesmo fazendo uma coletânea desse tipo de arte, fica aterrorizado com a monstruosidade dos quadros ao ponto de sequer conseguir descrevê-los, pois "o horror blasfemo e a inacreditável repulsa e decadência moral vinham de toques discretos, muito além do poder descritivo das palavras" (LOVECRAFT, 2015, p.100). Aqui temos um outro tema recorrente em Lovecraft, que é o do vazio da linguagem perante o terror absoluto. Thurber não pode realmente descrever as telas, assim como os monstros da mitologia de Lovecraft chegam a possuir nomes impronunciáveis, como o terrível Cthulhu. São propostos exatamente para semantizar a limitação humana perante a vastidão do universo (o que Lovecraft busca enfatizar com essas criaturas de proporções gigantescas habitando cidades de geometria não euclidiana, conforme "O Chamado de Cthulhu", ou de arquitetura desconhecida à humanidade, conforme Nas montanhas da loucura). E é exatamente esse encontro com o impronunciável, com o que a linguagem não dá conta, que causa a perturbação mental nas personagens, homens da modernidade, da razão, professores universitários e críticos de arte. Conforme Rosemary Jackson destaca (1998, p.38-39):

O abismo entre o signo e o significado, que se tornou uma questão dominante do modernismo, é antecipado por muitos trabalhos pós-românticos em um modo fantástico [...] As fantasias de horror de H. P. Lovecraft são particularmente conscientes em sua ênfase na impossibilidade de nomear esta presença inominável. (tradução nossa)

Vivian Ralickas, em um estudo que trata justamente da forma como os protagonistas de Lovecraft lidam com a arte, afirma que eles 
têm dificuldade em manter um distanciamento objetivo necessário para a apreciação artística, constituindo, então, uma relação de veneração religiosa com os artefatos artísticos que encontram:

Em vez de incitar uma reação intelectual do espectador culto, a ekphrasis em Lovecraft torna evidente que as propriedades formais da arte provocam uma explosão emocional que, em consequência de sua base sensível, é análoga à experimentada pelos incultos que percebem os objetos em termos de arte sacra. (RALICKAS, 2008, p.301 - tradução nossa)

Em "O Modelo de Pickman", a arte revela o horror sobrenatural de seu modelo. A princípio, o narrador não sabe que as pinturas são miméticas, isto é, são de modelos demoníacos reais, porém, seu conhecimento como crítico de arte lhe faz perceber que ele está diante de obras desconcertantemente realistas:

[...] era o pandemônio encarnado, claro e objetivo como um cristal. Céus! Aquele homem não era um romântico ou um fantasista, não! [...] era, em todos os sentidos [...] um realista talentoso, esmerado e quase científico. (LOVECRAFT, 2015, p.103)

Mas como poderiam ser reais coisas tão monstruosas e blasfemas? Esse efeito desconcertante de realidade torna-se ainda mais estarrecedor no momento em que Pickman revela a Thurber uma pintura enorme que, por fim, faz com que o experiente crítico de arte grite como uma criança assustada (LOVECRAFT, 2015, p.104), e tenha que fazer força para conter uma gargalhada histérica, já um indicativo de sua perturbação mental diante do acontecimento (LOVECRAFT, 2015, p.104). Thurber descreve o monstro no quadro; no entanto, não é a descrição, o conteúdo 
grotesco, que importa, mas uma afirmação que parece difícil de se compreender em uma primeira leitura, ao dizer que o mais terrível era a técnica de Pickman:

Era a técnica, Eliot - aquela técnica ímpia, maldita, sobrenatural! Assim como eu estou vivo, em nenhuma outra ocasião vi o sopro da vida tão presente em uma tela. O monstro estava lá roendo com raiva e com raiva roendo - e eu sabia que só uma suspensão das leis da Natureza poderia facultar a um homem pintar uma coisa daqueles sem ter um modelo - sem vislumbrar o mundo das profundezas jamais vislumbrado pelos mortais que não venderam a alma ao Diabo. (LOVECRAFT, 2015, p.104)

A técnica que era o problema, pois para o olho treinado do crítico de arte acostumado com o mórbido, aquela técnica revelava que alguma coisa sobrenatural e horrível estava acontecendo, dando a certeza de que apenas uma suspensão das leis da natureza poderia permitir que Pickman pintasse com aquele realismo sem um modelo. E é justamente essa suspensão de que fala Lovecraft em sua definição do horror cósmico, que Thurber sente, e é por isso que o conto "O modelo de Pickman" pode ser visto - ele próprio como modelo para o próprio sentimento de horror que Lovecraft desejava causar com sua ficção.

A revelação ao final do conto, quando Thurber vê que a fotografia que ele havia pegado sem notar não era apenas de um fundo de cenário, mas do próprio ser monstruoso posando para ser pintado por Pickman, apenas serve para confirmar o que o/a leitor/a mais atento já havia percebido. Que o realismo da técnica pictórica de Pickman se dava por ele não estar inventando as 
criaturas monstruosas, mas pintando-as a partir de modelos vivos. Daí o título do conto, "O modelo de Pickman", também ele mais uma peça ambígua da narrativa multifacetada de Lovecraft: o modelo, que pode ser tanto aquele que se deixa registrar quanto aquele se assume a função de um tipo, ao mesmo tempo condensação e excesso de significação.

Em sua teorização sobre o gênero conto, Ricardo Piglia afirma que "um conto sempre conta duas histórias" (PIGLIA, 2004, p.89). O conto "O Modelo de Pickman" apresenta, num primeiro nível, uma narrativa da visita do crítico de arte Thurber ao estúdio secreto de Pickman para ver quadros de pinturas macabras, mas remete, num segundo nível, à história de um pintor que convoca como seus modelos não são figuras imaginadas, mas monstros reais de um mundo oculto e subterrâneo. Piglia também afirma que "Um relato visível esconde um relato secreto, narrado de um modo elíptico e fragmentário. O efeito de surpresa se produz quando o final da história secreta aparece na superfície" (PIGLIA, 2004, p.89). É exatamente o que podemos ver ao final de "O Modelo de Pickman". O efeito de surpresa ao final da história de fato acontece, embora possam haver também leitores/as que desvendem o mistério antes da revelação do conteúdo da fotografia: que os monstros não eram fruto da imaginação de Pickman e sim modelos vivos (de fato, ele chega a dizer do quadro enorme que o monstro estava lá, com suas garras, olhos, hálito, grunhidos de ódio). Independente, porém, do/a leitor/a descobrir a história secreta apenas ao final ou antes disso, o fato é que toda a narrativa foi construída de forma progressiva para criar um ambiente de horror, até chegar no seu clímax que produz, na extensão enxuta e na característica gradação em 
crescendo do conto, aquilo que Poe (2009, p.116) defendia como "unidade de efeito" -, na verdade horrível desvelada na imagem, das monstruosidades ocultas que derrubam a humanidade de sua soberba posição de estar em um suposto ápice evolutivo ou de ter controle absoluto sobre o mundo.

\section{REFERÊNCIAS}

BARTHES, Roland (1984). A câmara clara. Nota sobre a fotografia. Rio de Janeiro: Nova Fronteira.

CESERANI, Remo (2006). O fantástico. Nilton Cezar Tridapalli (Trad.). Curitiba: Ed. UFPR.

CORTAZAR, Julio (1993). Valise de Cronópio. João Alexandre Barbos e Davi Arrigucci Jr. (Trad.). São Paulo: Perspectiva.

DELUMEAU, Jean (1993) História do medo no Ocidente, 1300-1800: Uma cidade sitiada (2a reimp.). Maria Lucia Machado (Trad.). São Paulo: Companhia das Letras. GINZBURG, Carlo (1991). "Das trevas medievais ao black-out de Nova lorque". In: A micro-história e outros ensaios. Lisboa: Difel.

JACKSON, Rosemary (1998). Fantasy: The literature of subversion. London and New York: Routledge.

JOSHI, Sunand Tryambak; SCHULTZ, David (2001). An H. P. Lovecraft encyclopedia. Westport: Greenwood Press.

LOVECRAFT, Howard Philips (2015). "Nas Montanhas da Loucura”. In: Os melhores contos de H. P. Lovecraft. Guilherme da Silva Braga (Trad.). São Paulo: Hedra.

. (2015). "O Chamado de Cthulhu". In: Os melhores contos de H. P. Lovecraft. Guilherme da Silva Braga (Trad.). São Paulo: Hedra.

. (1987). O horror sobrenatural na literatura. João Guilherme Linke (Trad.). Rio de Janeiro: Francisco Alves.

. (2015). "O Modelo de Pickman". In: Os melhores contos de H. P. Lovecraft. Guilherme da Silva Braga (Trad.). São Paulo: Hedra.

PIGLIA, Ricardo. (2004). Formas breves. José Marcos Mariani (Trad.). São Paulo: Cia. das Letras. 
POE, Edgar Allan (1986). "O homem das multidões". In: Fiç̧ão completa, poesia \& ensaios 4.ed. Oscar Mendes (Trad.). Rio de Janeiro: Nova Aguilar. . (2009). "A filosofia da composição". In: Poemas e ensaios. 4ed. Oscar Mendes e Milton Amado (Trad.). São Paulo: Globo.

PROHÁSZKOVÁ, Viktória (2012). "The genre of horror". In: American International Journal of Contemporary Research, vol. 2, n. 4, p.132-142.

RALICKAS, Vivian. (2008). "Art, cosmic horror, and the fetishizing gaze of H. P. Lovecraft". Journal of the fantastic in the arts, vol. 19, n. 3, p.297-316.

ROAS, David (2014). A ameaça do fantástico. Aproximações teóricas. Juliana Fuks (Trad.). São Paulo: Unesp.

SEDERHOLM, Carl (2006). "What screams are made of: representing cosmic fear in H. P. Lovecraft's 'Pickman's model'". In: Journal of the fantastic in the arts, vol. 16, n. 4, p.335-349.

TODOROV, Tzvetan. (1994). Introdução à literatura fantástica. Maria Clara Correa Castelo (Trad.). 2.ed. São Paulo: Perspectiva. 